\title{
Language learning difficulties of selected foreign students in National University, Philippines
}

\author{
Ancheta, Jeffrey Rosario $\measuredangle$ \\ National University, Philippines (jrancheta@national-u.edu.ph) \\ Perez, Cristopherson Arce \\ National University, Philippines (perezcristopherson@yahoo.com)
}

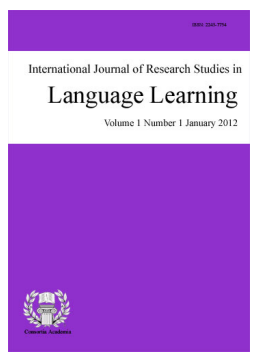

ISSN: 2243-7754 Online ISSN: 2243-7762

OPEN ACCESS

\section{Abstract}

This paper determined and analyzed the difficulties faced by the foreign students of National University in learning the Filipino language. Data gathered from ten (10) selected foreign students through interview were analyzed to find out the difficulties faced by the participants. An evaluation of the responses yielded the following difficulties: (1) difficulty of learning two languages at the same time, i.e., the English and Filipino (they recognized it as Tagalog) languages which are used as media of instruction; (2) reluctance of other students to communicate with them; (3) lack of any professor to provide enough time to teach them Filipino; (4) absence of any friend to assist them in translating Filipino sentences to English; (5) non-existence of a Filipino course to specifically address their language needs; (6) semantical and interpretational differences between Filipino and English; (7) lack of knowledge on the structure of Filipino language; (8) inadequacy of language learning materials such as books, modules, etc.; (9) embarrassment in speaking in Filipino; and (10) cultural differences. In line with the foregoing, a quadratic model of language learning has been specifically developed for the difficulties faced by the participants. Notwithstanding the difficulties, foreign students in National University are still eager to learn more about the Filipino language to keep up with the flow of conversation among campus students.

Keywords: language learning difficulty; Filipino language; foreign students; national university; quadratic model of language learning 


\section{Language learning difficulties of selected foreign students in National University, Philippines}

\section{Introduction}

Amidst of unbridled globalization, the Philippines continues to provide quality education not only to the Filipinos but also to foreign students. In the 1980s, the government began drawing foreign students to study in the Philippines, mostly in the fields of medicine and agriculture. A decade later, many schools and institutions offered short-term courses in English language, aviation, hotel and restaurant management, and maritime studies. In 2000, the Philippines have become an educational center in Asia; hence, foreign students had an easier time to apply for visas. Moreover, the Philippine government also established exchange programs between local universities and foreign universities, specifically those located in Australia, United States, South Korea, Canada, and Europe (Tempo, 2012).

Due to the foregoing, an increase in the number of foreign students in Philippine tertiary institutions has been witnessed. For instance, a number of 2,323 in 2001 has risen to 5,136 in 2006; however, a 48 percent decline has been notable in 2008 with only 2,665 (Tayag, 2013). Despite the major decline, the number of foreign nationals in different higher education institutions in the Philippines has rebounded to 7,776 in 2011 (CHED, online). The Philippine Bureau of Immigration affirms that the increasing number of foreigners studying here is a proof that the Philippines is fast emerging as a major educational hub in the Asia-Pacific region. The fact that more and more foreigners are opting to study in the Philippines is testament to the improving standard and the quality of education provided by the country's learning institutions (Aning, 2011).

Regardless, the comprehensive usage of the Filipino language in the country is inevitable. Aside from the fact that the national language of the Philippines is Filipino as governed in Sections 6-9, Article XIV of the Philippine Constitution, code-switching between Filipino and English has been relevant in the academic settings. The growing trend in code-switching is still the subject of a heated debate between academicians. However, as Bernardo (2005) argues, it can be a "legitimate and potent resource for learning and teaching for bilingual students and teachers" and that Filipinos should just relax (rather than strictly implement) language prescription in formal classes to enable both students and teachers in developing their understanding of topics.

Provided the comprehensive usage of Filipino within the Philippines, foreign students are now experiencing problems in classroom discussions wherein Filipino language is used as a medium of instruction. Learning a second language currently becomes essential for foreign students. As Cook (1996) states, knowing another language may mean getting a job, a chance to get educated, the ability to take a fuller part in the life of one's own coming on the opportunity to emigrate to another; an expansion of one's literary and cultural horizons; the expression of one's political opinions or religious beliefs.

\subsection{National University and its Foreign Students: At a Glance}

National University is a non-sectarian and co-educational institution in Manila, Philippines that is engaged in a continuous modernization and upgrading program for its facilities, faculty and sports development. It was established in 1900 as Colegio Filipino, which caters a handful of elementary and secondary students at that time. After five years, the institution offered courses in Business - bookkeeping and accounting that led to the changing of the name to Colegio Mercantil. In 1916, the Board of Trustees changed Colegio Mercantil to National Academy and its continuous growth paved their way to offer Liberal Arts, which became the gateway to other disciplines that followed. After giving 21 years of educational service since the institution started, the name National Academy transformed to National University. Thereafter, different programs had been offered to provide the needs of the students. Some of these were engineering and architecture courses, nursing, computer 
studies, and hotel and restaurant management (National University, online).

As to date, it has nine colleges such as Architecture, Engineering, Education, Arts and Sciences, Pharmacy, Nursing, Business and Accountancy, Computer Studies, Dentistry, and Hospitality Management, which offer different programs for its local and foreign students. Meanwhile, the number of foreign students at the National University has been notable. For the first semester of AY 2016-2017, the foreign students studying in National University reached a total of 90 (refer to Table 1). By nationality, the top foreign nationals studying are Eritrean, Sudanese, Iranian, Yemeni and Somali.

\section{Table 1}

Distribution of Foreign Students in National University by Nationality SY 2016-2017

\begin{tabular}{lc}
\hline \multicolumn{1}{c}{ Nationality } & Number of Students Enrolled \\
\hline Eritrean & 22 \\
Sudanese & 13 \\
Iranian & 12 \\
Yemeni & 8 \\
Somali & 6 \\
Chinese & 4 \\
Palestinian & 3 \\
American & 3 \\
Cameroonian & 3 \\
Korean & 3 \\
Egyptian & 2 \\
Indian & 2 \\
Other Nationality: & 9 \\
(Angolan, Arabian, Australian, Congolese, Ethiopian, & \\
Japanese, Portuguese, Senegalese, Taiwanese) & Total \\
& \\
\hline
\end{tabular}

Due to the growing population of foreign students in National University and the problems they are facing in learning the Filipino language, there exists a crucial need for a study which will determine and analyze the difficulties being encountered by them in learning Filipino.

It also aims to answer the following questions:

$>\quad$ What are the reasons of the participants in studying in the Philippines?

$>\quad$ What are the problems encountered by the participants in learning the Filipino language?

$>\quad$ What are the reasons of the participants in studying the Filipino language?

\section{Review of Related Literature}

\subsection{Factors affecting Second Language (L2) Learning}

For years, theories regarding L2 learning have been divergent on the concept of biological innateness (based on Chomskian perspective) or sociopsychology and social factors (Pavlenko, n.d.). On the other hand, the convention of a linear relationship between factors (which arises from reductionism) and L2 learning has been rebutted by new researches claiming the dynamism and complexity of these factors through the use of the Chaos/Complexity Theory (Safari \& Rashidi, 2015). Hence, the field of L2 learning research has been becoming more considerable of various factors (social, biological, behavioral, sociopsychological, self-image, etc.) in determining an individual's capacity to learn a second language.

Studies conducted during the $20^{\text {th }}$ century have provided significance (through model construction) on sociopsychological factors that focus on individual undertaking such as attitude, motivation, and innate capacity 
of the mind (Pavlenko, n.d.; Safari \& Rashidi, 2015; Cook, 2013). Some of the most famous models of language learning include the pioneering Universal Grammar (UG) of Chomsky (1966), Competition Model of MacWhinney (1987), Behaviorism of Skinner (1940's), Monitor Theory of Krashen (1987), Adaptive Control of Thought of Anderson (1983), Conversation Theory, Cognitive Theory,and Sociocultural Theory of Vygotsky (Malone, 2012; Cook, 2013; Second Language Theories, n.d.).

Though these studies are backed by logical arguments, often they present conflicting views. For instance, the Universal Grammar of Chomsky claims the innate capacity of an individual to learn a language; hence, automatic registration of language patterns is an inherent characteristic of every individual. Chomsky's theory has been rebutted by the emergence of the Competition Model which states of the "dynamic processing and communication" rather than mere knowledge to learn a language. The competition model focuses on how an individual utilizes a language rather than on what is built-in on his mind. It also introduced the four aspects of languages namely: word order, vocabulary, word forms, and intonation which compete against each other or which is used at the expense of the other depending on the language an individual pursues to communicate.

Aside from the Competition model, various models have also contradicted Chomsky's. The Adaptive Control of Thought by Anderson has explained that language learning is a result of a "highly complex cognitive structure" which is produced through the gathering and fine-tuning of knowledge units. It also claims the procedural aspect of language learning rather than the declarative knowledge alone which is already stored in the mind. Hence, practice (procedural aspect) is essential to achieve language learning. Anderson's findings have provided enough support to the Behavioral theory of Skinner, which is also called S-R-R (stimulus, response, and reinforcement). The theory suggests that language learning is like any other behavior which can be learned through S-R-R until it becomes a habit (Malone, 2012).

Various language professionals in the likes of Krashenn, Schumann, and Vygotsky have become popular due to their revolutionary views both in language learning and L2 learning. Stephen Krashen's Theory of Second Language Acquisition, Schumann's Acculturation Theory, and Vygotsky's Sociocultural theory which all consider social interaction as an integral part of L2 learning have been the persisting bases of modern L2 research. Krashen's theory focuses on five main hypotheses namely: Acquisition-Learning, Monitor, Natural Order, Input, and Affective Filter.

With some incorporation from previous researches regarding biological innateness and actual communication, Krashen has addressed (through the input and Affective Filter hypotheses) the factors affecting L2 learning. The input hypothesis claims that a learner develops in a "natural order" if he receives a "second language input" which is a step higher than his current linguistic competence. On the other hand, the Affective Filter hypothesis provides three important variables (motivation, self-confidence, and anxiety) towards a/an (un)successful L2 learning. Learners with high motivation, high self-confidence, and low anxiety become successful L2 learners because they efficiently acquire the second language inputs (Stephen Krashen's Theory, n.d.; Malone, 2012). Schumann's Acculturation Theory and Vygotsky's Sociocultural Theory consider social interaction as a significant factor towards successful L2 learning. In acculturation, consideration shall be made in the sociological, political, and context of the learner towards successful L2 learning. The readiness of the target language group and a low affective filter (in support of Krashen) become the primary determinants of successful L2 learning (Second Language Theories, n.d.).

On the other hand, the Sociocultural Theory emphasizes the relationship between mental functioning and the social, cultural, and historical situations where the functioning happens. Through its three important concepts (Mediation, Zone of Proximal Development, and Scaffolding), the theory argues that L2 learning occurs through a social interaction (mediation) when there is a gap between an individual's actual developmental level and potential level (Zone of Proximal development) that he can attain through the assistance (scaffolding) of a more capable individual (Safari \& Rashidi, 2015). These approaches are popularly referred to as "poststructuralist approaches" since they reconceptualise L2 learning as "intrinsically social" rather than "simply cognitive" which 
concept is referred to as "situated learning (Pavlenko, n.d.)."

Due to the conflicting ideas, continuous dynamism of L2 learning, and its relativity to every individual, the Chaos/Complexity Theory (C/CT) has been formulated. Under this theory, L2 learning is considered as a complex nonlinear system. Hence, it is "dynamic, nonlinear, chaotic, unpredictable, sensitive to initial conditions, open, self-organizing, feedback sensitive, and adaptive (Larsen-Freeman, 1997, as cited in Tamjid, n.d.).” A C/CT model views L2 learning as something which no particular theory can explain due to its complexity. However, different theories (whether nativist such as Chomsky's, Input-based such as Krashen's, Environmental such as Skinner's, or Interactionist such as Anderson's) can be integrated into a whole for a better understanding of the process (Safari \& Rashidi, 2015; Theories of L2, n.d.).

\subsection{Difficulties in L2 Learning}

Related studies have provided findings relating to difficulties in L2 learning (Banks, 2008; Tabatabaei \& Loni, 2015; Rizi, Siddiqui, Moghaddam, \& Mukherjee, 2014; Ebrahimpourtaher \& Eissaie, 2015; Ameri \& Asare, 2010; Ramezani, Dehgahi, \& Hashemi, 2015). Major findings in Bank (2008, p.62), whose study involves high school students who are unsuccessful in their foreign language (FL) classes, include the following: (1) student's FL difficulties may actually stem from English deficiencies; (2) students may be unable to identify their learning styles and/or self-determine what strategies to employ in order to be successful; (3) students who perceive themselves as less capable, possessing fewer skills, and having a negative attitude may produce low output as a result of giving up; (4) students may have low motivation due to past failures if they don't see the connection between their lives and class lessons; (5) high anxiety about the class may cause students to raise an affective filter, which blocks FL input, and impairs memory, organization, and spontaneous oral production; and (6) students may have inabilities to convert input into intake, because they are unclear about class norms, procedures, grading, or other expectations.

Moreover, the study recognizes the radical change of teaching methods in foreign language classes. Nowadays, the public demands teachers to employ a variety of strategies such as natural approach, communicative activities, technology, multi-sensory technique, etc. However, despite the conscious efforts for these strategies, language difficulties still arise due to a disparity between learner's styles or patterns and teaching methodology. This mismatch serves as the ultimate cause of problems in L2 learning aside from personality, cognition, and feelings (Ehman, 1996). For instance, in the study of Ramezani et al. (2015), learning styles preferences of Iranian students turn out to be different based on gender. Female students prefer auditory learning the most; male students prefer kinesthetic learning the most. Female students have least preference on kinesthetic learning; male students have least preference on tactile learning. Given such, if the two genders will be exposed on the same methodology, they may not learn in the most efficient way or one gender will learn at the expense of the other. On the other hand, a study conducted by Schuetze (2016) argued that female students have higher word retention rates compared to male students if the words have been repeated five times. He also found out that the estrogen hormone (which stimulates serotonin production) has no significant effect to the retention of emotional words though serotonin is closely linked to emotions, particularly happiness.

Multi-sensory instruction methods and project-based assessments in lieu of standardized tests are also encouraged by Banks. Despite the growing trend of communicative approaches and de-emphasis in grammar teaching, at-risk students and students with learning disabilities (respondents) shall also be instructed explicitly of grammar and phonology (Banks, 2008). Findings and suggestions by Banks (2008) can provide guidance to the difficulties experienced by high school students in the study of Tabatabaei and Loni (2015). The study argues that, in the Lorestan Province (located in Iran) High Schools' context, the availability of educational facilities does not have a significant relationship to the quality of the sample's L2 learning. However, an implication has been made-there exists bigger problems aside from educational facilities. Lack of target language use in class, restricting the evaluation merely to midterm and final exams, classes being overcrowded, the absence of language laboratories, and also the mere use of textbook ignoring any inclusion of supplementary materials such 
Ancheta, J. R., \& Perez, C. A.

as CDs, movies, and other instructional aids are the problems which hinder L2 learning.

The utilization of movie materials has been the subject of Garnier (2013). She argued that watching DVDs under reversed subtitling conditions (L1 audio and L2 subtitle) tends to be effective towards intentional vocabulary learning. In the first few hours of watching, a very poor uptake rate per hour has been observed. Hence, participants watching DVDs under reversed subtitling conditions retain the words even after months of watching the movie; however, immediate retention of the words cannot be achieved. In support with Tabatabaei and Loni (2015), Rizi et al. (2014) have found a correlation between access to audio-visual aids and linguistic competence in L2 through a comparative study of Indian and Iranian secondary students. Indian students have five times more access to audio-visual aids, newspapers, and magazines and are more interested to reading their textbooks as compared to Iranian students. Since Indian students have a wider extension in speaking the L2 (which is English) compared to Iranian students, access to these materials and reading interest can be implied to have affected their quality of learning.

Linguistic competence and native language can also impose difficulties on students enrolled in L2 classes. In the study of Ebrahimpourtaher and Eissaie (2015), Iranian intermediate L2 learners have considered grammar (as compared to vocabulary) as the most challenging yet the least useful part of L2 acquisition. Despite the grammatical difficulty, respondents recognized a need for first language usage or code-switching in order to assist them in understanding grammar and vocabulary. On the other hand, the native language may also hinder successful L2 learning. For instance, Ameri and Asareh (2010) argued that due to the fact that Turkish and Arabic languages did not arise from the same language branch as Persian, bilingual elementary students enrolled in Persian languages encounter troubles in subject-verb agreement, verbal inflections, syntax, and semantics.

In contribution to the field of second language research, this study has been undertaken in order to assess the language learning difficulties of foreign students in the Philippine setting. The researchers believed that L2 learning difficulties faced by foreign students in the Philippines have not been addressed that much. Studies conducted from other countries can provide guidance into this research. In effect, if these problems will be identified through this research, certain alternatives can be suggested in order to address them.

\section{Methodology}

This study is an exploratory research that aims to analyze the difficulties of foreign students in learning the Filipino language. The conduct of the study was done through an interview. Ten (10) foreign students of different nationalities were randomly selected as subjects for this study (refer to Table 2). All the information is accurate except for their names to protect their identities.

Table 2

Profile of the Participants

\begin{tabular}{|c|c|c|c|c|c|}
\hline Name & Age & Nationality & $\begin{array}{c}\text { First } \\
\text { Language }\end{array}$ & Course & $\begin{array}{c}\text { Length of Stay in the } \\
\text { Philippines }\end{array}$ \\
\hline Ahmed & 19 & Eritrean & Tigrigna & Electrical Engineering & 1 year \\
\hline Saeed & 21 & Eritrean & Tigrigna & Civil Engineering & 9 months \\
\hline Masafa & 20 & Palestinian & Arabic & Civil Engineering & 8 months \\
\hline Ahleb & 22 & Yemeni & Arabic & $\begin{array}{l}\text { Electronic Communication } \\
\text { Engineering }\end{array}$ & 1 year \\
\hline Moud & 26 & Palestinian & Arabic & Architecture & 3 years \\
\hline Azi & 21 & Sudanese & Arabic & Dentistry & 1 year and 3 months \\
\hline Mohan & 18 & Egyptian & Arabic & Civil Engineering & 5 months \\
\hline Fabie & 19 & Cameroonian & French & Marketing Management & 3 years \\
\hline Jumong & 22 & Korean & Korean & AB English & 10 months \\
\hline Jam & 22 & Sudanese & Arabic & Electrical Engineering & 3 years \\
\hline
\end{tabular}

To determine the difficulties of foreign students in learning the Filipino language, each participant 
underwent an interview which lasted for 30-minutes. The researcher used the English language as a medium, despite the apparent lack of proficiency and presented difficulty of the foreign students in using the English language. English, similar to Filipino, is also a second language for them. The interviews were conducted during the most convenient time and place of the foreign students and were audio-recorded with the participant consent. It was later on transcribed and analyzed.

\section{Findings}

The participants are aware that National University is not a strictly English-speaking institution. They are also aware that the university will require them to take 6-9 units of Filipino course work focusing on communication and macro skills, reading and writing towards research, and rhetoric. However, they still choose to study in the Philippines mostly because of the quality education that the universities could offer at a more affordable tuition and miscellaneous fee compared to that of their respective countries (refer to Table 3 ).

\section{Table 3}

Reasons for Studying in the Philippines (National University)

\begin{tabular}{ll}
\hline Name & \multicolumn{1}{c}{ Reasons } \\
\hline Ahmed & $\begin{array}{l}\text { "My family decided to study in the Philippines because it has a good quality education than other } \\
\text { places." }\end{array}$ \\
$\begin{array}{l}\text { Saeed } \\
\text { Masafa }\end{array}$ & $\begin{array}{l}\text { "Family requirements." } \\
\text { study not just because of the new culture, but for improving my English as well as learning a new }\end{array}$ \\
& $\begin{array}{l}\text { language which is Tagalog and of course the school fees have a massive difference in price } \\
\text { compared to my country." }\end{array}$ \\
Ahleb & "Philippines society is so kind and education is cheap." \\
Moud & "Because Philippines is cheap country." \\
Azi & "Because it's cheap and I want to know how to speak English." \\
Mohan & "Because it's cheap." \\
Fabie & "Uh... good education." \\
Jumong & "Filipino education fee is important in Korea." \\
Jam & "I choose Philippines because my brother graduated here and it is cheaper." \\
\hline
\end{tabular}

Since National University does not have a strict language policy, most of the professors are using both English and Filipino languages in their class discussion. Given their current situations, several difficulties have been experienced by foreign students in learning Filipino (refer to Table 4).

\section{Table 4}

Difficulties Encountered by the Participants in Filipino Language Learning

\begin{tabular}{cl}
\hline Name & \multicolumn{1}{c}{ Difficulties } \\
\hline Ahmed & "The problem that I had is memorizing and pronunciation because I'm still new in the \\
Saeed & Philippines." \\
& "The way to spill the words. It's so hard to say it and remember it. I have no tutor or friends to \\
& study Tagalog. Uh... It is hard especially me from Africa. Filipino culture is also different and it \\
affects my learning." & "Being here in such a new country with a new language being spoken will make us foreigners a \\
Masafa & bit hard to learn. There is no formal classes for us on how to speak Tagalog. I have Filipino \\
& courses, but I feel isolated because the professor keeps on speaking in Filipino as if I am not \\
around. Uh... the subject also is quite hard. There is no basic Filipino for us foreigners." \\
"Some professors speak Tagalog, leading to foreign students don't pay attention to the professor. \\
Ahleb & $\begin{array}{l}\text { And I've faced some racist professors. They keep on laughing if I don't understand what they are } \\
\text { saying because it is not English. They use both English and Filipino in discussing things." }\end{array}$ \\
Moud & "It's hard for us to understand it because we are not familiar for this. It makes us headache if \\
Azi & some are talking Filipino. It's hard to speak for us." \\
& "I have problems because my English not that much and so Filipino, and my classmates doesn't \\
help me. I also have Filipino subject before, but professor don't have regular free time helping me & \\
& learn the language."
\end{tabular}


Ancheta, J. R., \& Perez, C. A.

Table 4 ... continued

Mohan "I have little problem like if I ask my classmates about something they can't help me because our English not that much. They tend to walk away if they notice that I am gonna ask help from them."

Fabie "Don't really have problems. I've been here since high school and I always ask help from my classmates and professors. But sometimes, they laugh if I say the Tagalog words incorrectly. It makes me feel down to the extent that I better keep silent that talking. It is shameful you know. But it's okay with me."

Jumong "Difficulties in grammar. It's hard to make sentence in Filipino. No books on how to create sentence. Filipino is different. It's hard to learn because I am also learning English."

Jam "The problem is that it's hard to pronounce the Filipino words correctly."

On the other hand, when asked if they still want to learn the Filipino language, all of them responded on the affirmative. The foreign students recognize learning the language as a need to fill the gap and break the barriers between foreign and local students (refer to Table 5).

Table 5

Perception of Learning the Filipino Language

\begin{tabular}{|c|c|}
\hline Name & Reasons of Learning Filipino Language \\
\hline Ahmed & "I would like to try my best to learn it so that I can have a new language that I can speak." \\
\hline Saeed & "Yes. I still want because I can have a maganda (beautiful) girlfriend." \\
\hline Masafa & $\begin{array}{l}\text { "For sure we still need to learn it and we would love to, it's really helpful to get along with people } \\
\text { and make them comfortable to talk with you and being one of them, although it's a commonly } \\
\text { used language in Saudi Arabia because of the Filipino people who are working there." }\end{array}$ \\
\hline Ahleb & $\begin{array}{l}\text { "Yes because some Filipino people they speak English and Tagalog but when you speak their } \\
\text { language they get more a bit kindly. And you can make relationship here by simply speaking their } \\
\text { language." }\end{array}$ \\
\hline Moud & $\begin{array}{l}\text { "Yes so that we will know and no one can talk behind us and its easy for us to deliver what we } \\
\text { have and its a additional knowledge for us". }\end{array}$ \\
\hline Azi & $\begin{array}{l}\text { "Yes I want because I can understand my professor and my friends what they said and also to talk } \\
\text { with anyone." }\end{array}$ \\
\hline Mohan & "Yes I want learn more Tagalog because I can answer about my problems." \\
\hline Fabie & "Yes, because I live here and I will stay here for long." \\
\hline Jumong & "Yes because after I graduate, if I go here, I get know how to speak in Tagalog." \\
\hline Jam & "I would like to try my best to free myself and learn how to use the language." \\
\hline
\end{tabular}

\section{Discussion}

The study revealed that foreign students studying in National University experience difficulties in Filipino language learning. Using the data gathered from the participants, the Filipino language learning difficulties are shaped with quadratic relationship of linguistic competence, academic reinforcement, social motivation, and emotional factor.

\begin{tabular}{c|c}
$\begin{array}{c}\text { Language } \\
\text { Competence }\end{array}$ & $\begin{array}{c}\text { Academic } \\
\text { Reinforcement }\end{array}$ \\
\hline Social & Emotional \\
Motivation & Factor
\end{tabular}

Figure 1. Quadratic Model of Language Learning

\subsection{Linguistic Competence}

Linguistic competence refers to the ability to use the language code or system itself and all its component 
parts such as grammar, phonology, graphology and lexis (Smolcic, n.d.). It is also defined as the capacity of an organization and its personnel to communicate effectively, and convey information in a manner that is easily understood by diverse audiences, including persons of limited English proficiency (LEP), those who have low literacy skills or are not literate, and individuals with disabilities (Chu \& Goode, 2009).

Results show that most of the participants encountered several difficulties such as learning two languages at the same time - the English and Filipino (they recognized it as Tagalog) languages, confusion about the meaning of the sentence because there are words in English that have many interpretations when translated into Filipino, and lack of knowledge on the structure of Filipino language. Addressing linguistic competence issues would involve the determination of proper techniques towards the efficient language learning of the students. For instance in the study of Bouchhioua (2016), second language pronunciation has improved significantly through a focus in the segmental and suprasegmental features of the language as compared to the traditional Audiolingual method employed in universities. However, the group subjected to the suprasegmental treatment achieved better results than those subjected in segmental treatment.

\subsection{Academic Reinforcement}

Linguistic competence requires organizational and provides capacity to respond effectively to the needs of populations served. The organization must have policy, structures, practices, procedures and dedicated resources to support this capacity (Chu \& Goode, 2009). In the case of foreign students in National University, results show that the university has no concrete policy and practices that will help the foreign students to learn the Filipino language. The absence of formal courses on basic Filipino language specifically designed for their needs, lack of any professor who possess enough time to teach them, and the inadequacy of language learning materials such as books, modules, etc. are some of the learning difficulties arising from insufficient academic reinforcement.

For them to learn the Filipino language, the university must create programs that will hone the participants' understanding and speaking and writing skills in Filipino language. The university should formulate a specific course such as Basic Filipino Conversation course for the foreigners instead of giving them higher Filipino courses. As an academic institution, National University plays a vital role in reinforcing the language learning of the participants. Even if the foreign students will not directly use the language in their country of origin, learning the Filipino language is essential towards social interaction with local individuals which interaction remains as their top reason for continuously learning Filipino.

\subsection{Social Motivation}

Social motivation refers to the human need to interact with other humans and to be accepted by them. These interactions are considered to be social behaviors that address, either directly or indirectly, other people with the purpose of soliciting a response (Social motivation, n.d.). The term motivation refers to factors that activate, direct, and sustain goal-directed behavior. Motives are the "whys" of behavior - the needs or wants that drive behavior and explain what we do. We don't actually observe a motive; rather, we infer that one exists based on the behavior we observe (Nevid, 2013). Difficulties relating to social motivation have been clearly reflected in the results. Results show that most of the participants encountered social rejection such as the reluctance of any student in communicating with them and the absence of a friend who will persistently help them in translating English to Filipino.

The society also plays an integral part in the desire of foreign students to learn the Filipino language. For example, Saeed stated that culture is a factor that affects his eagerness to learn more of the Filipino language. Believing he is in the Philippines and he needs to adjust, he needs to follow the predominant culture. In Fabie's case, on the other hand, he wanted to learn the language and believed he can do it because his friends help him to speak Filipino. Social motivation has then become their primary reason to continue learning Filipino. Hence, 
social motivation can be implied as an important factor towards second language learning. Indeed, the society and context shall be taken into consideration in order to address learning difficulties. In the study of Ghafar Samar and Dehqan (2012), low proficiency learners (experimental or sociocultural group) have manifested better reading comprehension development than the high proficiency learners (control group). Therefore, sociocultural techniques can be employed to assist low proficiency learners or individuals during their early learning stages.

Aside from the society, the context shall also be considered. A cognitive model which considers the importance of context has been the subject of Ang (2013). As Ang (2013, p.46) puts it: Context plays a vital role in acquisition, in the sense that the amount of contextual information is crucial to the quality of instantiation performed.

\subsection{Emotional Factor}

Emotion is simply defined as a feeling towards a situation. It is a conscious mental reaction (as anger or fear) subjectively experienced as strong feeling usually directed toward a specific object and typically accompanied by physiological and behavioral changes in the body (Merriam Webster online, n.d.). According to Pekrun (2014), emotions profoundly influence learning and achievement. His research has shown that students experience many emotions during lessons, while studying, and when taking tests and examinations. These emotions can be positive or negative, and they can be intense and frequent. Some of these emotions are brought into the classroom from life outside the school. Many of them, however, originate within academic settings. Since the participants had experienced social rejections, they experience embarrassment in using the Filipino language. One of the participants also encountered a racist professor. The racial discrimination has led to his low self-esteem and disinterest in learning the Filipino language. Emotional setbacks which are presented in the study can lead to a reduction of risk-taking by the learner. Zafar and Meenakshi (2011) provides significance to the role of risk-taking to second language acquisition and language fossilization (a phenomenon wherein a second language learner retains his first language system and cannot be corrected if he learns a second language). They explained that risk-takers can easily adapt to a second language due to their resistance against fossilization. They also argued that risk-taking is influenced by classroom participation and that extroverts tend to be the ones who become risk-takers.

\section{Conclusion}

This study aimed to determine and analyze the Filipino language learning difficulties of the selected foreign students in National University. The researcher expounded and differentiated these problems through the development of a quadratic model which incorporates four factors namely: linguistic competence, academic reinforcement, social motivation, and emotional factor which affect the second language learning of the foreign students. However, a significant problem concerning the Filipino language learning of foreign students can be witnessed - the lack of a university program or curriculum which is specifically designed for their special language needs in Filipino. Based on the responses of the participants, their dependence to friends or classmates is the main action that they do in order to keep up with class topics and learn Filipino. Often, they cannot properly learn the language because the abovementioned practice can be difficult given the aloofness of other students to communicate with them. Although the dependency of foreign students with local students in language learning imposes no significant issue, having their own language program or curriculum tends to be more beneficial and holistic.

Acknowledgment: This manuscript was presented in the $4^{\text {th }}$ International Conference on Language, Education and Education held last March 19-20, 2016 in Ho Chi Minh City, Vietnam. We thank all the participants who provided insights to further enhance this manuscript for publication and to ICSAI.org for organizing the conference that served as our venue to exchange our research ideas and to learn from different discussion forum.

We would also like to extend our gratitude to the National University, Philippines especially Dr. Rachel Edita 
Language learning difficulties of selected foreign students in National University, Philippines

Roxas, Vice President for Academic Affairs and Director of NU Research and Innovation Office (NU RaIN); Dr. Jessie Barrot, Assistant Director of NU RaIN; Dr. Joel M. Durban, Dean of the College of Education, Arts and Sciences; and Dr. Glendora V. Tiu, Director of NU Internationalization Office and Chair of the Department of Humanities, Social Sciences, and Psychology, for giving one of the researchers the opportunity to participate in the said international conference. Thank you, Prof. Ivan Brian Inductivo for the careful review, and for the comments and corrections he gave to improve our paper. Without their help, this manuscript would not come this far.

\section{References}

Ameri, H., \& Asareh, F. (2010). An investigation about language learning problems at elementary levels in bilingual areas of Iran. Procedia-Social and Behavioral Sciences, 9, 1757-1761. http://dx.doi.org/10.1016/j.sbspro.2010.12.395

Ang, I. (2013). Rethinking the role of context and definition in second language vocabulary acquisition (SLVA): An assimilation via a cognitive model of concept formation. International Journal of Research Studies in Language Learning, 3(1), 33-50.

Aning, J. (2011). Philippines has 26k foreign students. Inquirer.net. Retrieved from http://globalnation.inquirer.net/9781/Philippines-has-26k-foreign-students

Banks, T. (2008). Foreign language learning difficulties and teaching strategies [PDF Document]. Retrieved from http://files.eric.ed.gov/fulltext/ED501062.pdf

Bernardo, A. B. I. (2005). Bilingual code-switching as a resource for learning and teaching: Alternative reflections on the language and education issue in the Philippines. In D. T. Dayag \& J. S. Quakenbush (Eds.), Linguistics and language education in the Philippines and beyond: A festschrift in honor of Ma. Lourdes S. Bautista (pp. 151-169). Manila, the Philippines: Linguistic Society of the Philippines.

Bouchhioua, N. (2016). The effects of explicit pronunciation instruction on the comprehensibility and intelligibility of Tunisian EFL learners. International Journal of Research Studies in Language Learning, 6(3), 73-88. http://dx.doi.org/10.5861/ijrs1l.2016.1480

Chu, Y. K. G., \& Goode, T. (2009). Cultural and linguistic Competence. Optometric care within the public health community. Cadyville, NY: Old Post Publishing.

Commission on Higher Education. (n.d.). Foreign students. Retrieved from http://www.ched.gov.ph/index.php/higher-education-in-numbers/foreignstudents

Cook, V. (2013). Second language learning and language teaching. Retrieved from https://books.google.com.ph/books?hl=en\&lr=\&id=Ma0uAgAAQBAJ\&oi

Ehrman, M. E. (1996). Understanding second language learning difficulties. Retrieved from https://books.google.com.ph/books?id=UqZ1AwAAQBAJ

Garnier, M. (2013). Intentional vocabulary learning from watching DVDs with subtitles: A case study of an 'average' learner of French. International Journal of Research Studies in Language Learning, 3(1), 21-32.

Ghafar Samar, R., \& Dehqan, M. (2012). Sociocultural theory and reading comprehension: The scaffolding of readers in an EFL context. International Journal of Research Studies in Language Learning, 2(3), 67-80.

Lightbrown, P. M., \& Spada, N. (2013). How languages are learned. Oxford: Oxford University Press.

Macaro, E. (2010). Continuum comparison to second language acquisition. London.

Malone, S. (2012). Theories and research of second language acquisition [PDF Document]. Retrieved from http://www.sil.org/sites/default/files/files/theories_and_research_of_second_language_acquisition.pdf

National University. (n.d.). Brief history. Retrieved from http://national-u.edu.ph/wordpress/about/

Nevid, J. (2013). Psychology: concepts and applications. Belmont, CA: Wadworth.

Pavlenko, A. (n.d.). Poststructuralist approaches to the study of social factors in second language learning and use [PDF Document]. Retrieved from 
Ancheta, J. R., \& Perez, C. A.

https://www.researchgate.net/profile/Aneta_Pavlenko/publication/265110112_Poststructuralist_Approa ches_to the_Study_of_Social_Factors_in_Second_Language_Learning_and_Use/links/56abaa8108ae4 3a39809ade4.pdf

Pekrun, R. (2014). Emotions and Learning. International Academy of Education and of Education. Belley, France: Gonnet Imprimeur.

Ramezani, A. E., Dehgahi, M., \& Hashemi, H. (2015). An exploratory study of the language-learning style preferences of Iranian EFL high school students. Advances in Language and Literary Studies, 6(2), 150-159.

Rizi, B. M., Siddiqui, M. A., Moghaddam, R. A., \& Mukherjee, S. (2014). Deficiencies in teaching and learning English as a foreign/second language in the secondary Schools of Iran \& India. IMPACT: International Journal of Research in Humanities, Arts and Literature, 2(6), 5-14.

Safari, P., \& Rashidi, N. (2015). Language learning as Chaos/Complexity system: Evidence based on Iranian EFL learners' backgrounds. Turkish Online Journal of Qualitative Inquiry, 6(4), 22-56. http://dx.doi.org/10.17569/tojqi.77606

Schuetze, U. (2016). Second language vocabulary acquisition: Male vs female learners and the role of words associated with emotion. International Journal of Research Studies in Language Learning, 5(4), 15-26. http://dx.doi.org/10.5861/ijrsp.2016.1520

Schumann, J. H. (1986). Research on the acculturation model for second language acquisition. Journal of Multilingual and Multicultural Development, 7(5), 379-392. http://dx.doi.org/10.1080/01434632.1986.9994254

Second Language Theories. (n.d.). Retrieved from https://ows.edb.utexas.edu/site/teaching-russian-e-portfolio/second-language-theories

Smolcic, E. (n.d.). Linguistic and pragmatic competence. Retrieved from http://elearning.la.psu.edu/aplng/802/lesson-3/5.2-four-areas-of-communicative-competence

Social Motivation. (n.d.). In Alleydog.com's online glossary. Retrieved from http://www.alleydog.com/glossary/definition-cit.php?term=SocialMotivation

Stephen Krashen's Theory of Second Language Acquisition. (n.d.). Retrieved from http://www.sk.com.br/sk-krash-english.html

Tabatabaei, O., \& Loni, M. (2015). Problems of teaching and learning English in Lorestan province high schools, Iran. Mediterranean Journal of Social Sciences, 6(2), 47-55. http://dx.doi.org/10.5901/mjss.2015.v6n2s1p47

Tamjid, N. H. (n.d.). Chaos/Complexity theory in second language acquisition. Novitas-ROYAL, 1(1), 10-17.

Tayag, J. C. (2013). The international mobility of students in Asia and the Pacific. Bangkok, Thailand: UNESCO. Tempo Online. (2012). Emerging education hub in Asia-Pacific. Retrieved from http://www.tempo.com.ph/2012/02/20/new/news-roundup/emerging-education-hub-in-asia-pacific/

Theories of L2 acquisition. (n.d.). Retrieved from http://www4.ujaen.es/ gluque/TOPIC5.pdf

Zafar, S. (2011). A study on the relationship between extroversion-introversion and risk-taking in the context of second language acquisition. International Journal of Research Studies in Language Learning, 1(1), 33-40. http://dx.doi.org/10.5861/ijrsll.2012.v1i1.42 